\title{
Warren, McCain, and Obama Needed Fuzzy Sets at Presidential Forum
}

\author{
Ashu M. G. Solo \\ Maverick Technologies America Inc., Suite 808, 1220 North Market Street, \\ Wilmington, DE 19801, USA \\ Correspondence should be addressed to Ashu M. G. Solo, amgsolo@mavericktechnologies.us \\ Received 26 March 2012; Accepted 8 April 2012 \\ Academic Editor: Madan M. Gupta \\ Copyright ( $(2012$ Ashu M. G. Solo. This is an open access article distributed under the Creative Commons Attribution License, \\ which permits unrestricted use, distribution, and reproduction in any medium, provided the original work is properly cited. \\ During a presidential forum in the 2008 US presidential campaign, the moderator, Pastor Rick Warren, wanted Senator John \\ McCain and then-Senator Barack Obama to define rich with a specific number. Warren wanted to know at what specific income \\ level a person goes from being not rich to rich. The problem with this question is that there is no specific income at which a person \\ makes the leap from being not rich to being rich. This is because rich is a fuzzy set, not a crisp set, with different incomes having \\ different degrees of membership in the rich fuzzy set. Fuzzy logic is needed to properly ask and answer Warren's question about \\ quantitatively defining rich. An imprecise natural language word like rich should be considered to have qualitative definitions, crisp \\ quantitative definitions, and fuzzy quantitative definitions.
}

\section{Introduction}

Certainty and precision are much too often used as an absolute standard in reasoning and decision making. Fuzzy logic [1-6] is based on the notion of relative graded membership and can deal with information arising from computational perception and cognition that is uncertain, imprecise, vague, partially true, or without sharp boundaries. Dr. Zadeh published his first famous paper [1] on fuzzy sets in 1965 . The theory of fuzzy logic was inspired by the processes of human perception and cognition. This tool for uncertainty management is extremely useful in approximate reasoning and decision making. Fuzzy sets are needed for quantitatively defining imprecise linguistic terms used in politics and public policy.

During the 2008 US presidential campaign, Pastor Rick Warren moderated the Saddleback Civil Forum on the Presidency [7] with then-Senator Barack Obama, who was the Democratic nominee for president, and Senator John McCain, who was the Republican nominee for president. Although McCain and Obama were questioned by Warren at the same event, McCain was not present while Obama was being questioned by Warren, and Obama was not present while McCain was being questioned by Warren. Warren separately asked McCain and Obama to define rich with a specific number. Warren wanted to know at what specific income level a person goes from being not rich to being rich. This was a ridiculous question for a presidential forum and caused everybody to laugh because the term rich cannot be defined so precisely as being greater than a single specific annual income. This is because rich is a fuzzy set, not a crisp set. Obama and McCain floundered and rambled in trying to answer Warren's question using crisp logic, as can be seen in the transcripts that follow. Warren needed fuzzy logic to properly ask his question. McCain and Obama needed fuzzy logic to properly answer Warren's question.

Similarly, middle class and poor are fuzzy sets, not crisp sets. Therefore, fuzzy logic is needed to properly ask and answer queries about quantitatively defining middle class and poor. Fuzzy sets have been used for imprecise linguistic terms in many intelligent systems applications, but this research paper proposes the use of fuzzy sets for the application of asking and answering queries about quantitatively defining imprecise natural language linguistic terms in politics and public policy. 


\section{Transcripts on Quantitatively Defining Rich with a Crisp Set at the Saddleback Civil Forum on the Presidency}

2.1. Transcript of Exchange between Warren and Obama on Quantitatively Defining Rich with a Crisp Set. A transcript of the exchange between Warren and Obama on quantitatively defining rich with a crisp set follows:

Warren: Okay. Taxes-this is a real simple question. Define rich. (Audience laughs.) I mean give me a number. Is it $\$ 50,000$ ? $\$ 100,000$ ? 200,000? Everybody keeps talking about who we're going to tax. How do you define that?

Obama: You know, if you've got book sales of $\$ 25$ million, then you qualify. (Audience laughs.) Yes.

Warren: No, I'm not asking about me.

Obama: Look, the-here's how I think about it. Here's how I think about it. And this is reflected in my tax plan. If you are making $\$ 150,000$ a year or less as a family, then you're middle class or you may be poor. But $\$ 150,000$ down you're basically middle class, obviously depends on the region where you're living.

Warren: In this region, you're poor.

Obama: Yes, well-depending. I don't know what housing practices are going. I would argue that if you're making more than $\$ 250,000$, then you're in the top three, four percent of this country. You're doing well. Now these things are all relative. And I'm not suggesting that everybody is making over $\$ 250,000$ is living on easy street.

But the question that I think we have to ask ourselves is, if we believe in good schools, if we believe in good roads, if we want to make sure that kids can go to college, if we don't want to leave a mountain of debt for the next generation, then we got to pay for these things. They don't come for free, and it is irresponsible-. I believe it is irresponsible intergenerationally for us to invest or for us to spend $\$ 10$ billion a month on a war and not have a way of paying for it. That, I think, is unacceptable. So nobody likes to pay taxes. I haven't sold 25 million books, but I've been selling some books lately, and so I write a pretty big check to Uncle Sam. Nobody likes it.

What I can say is that under the approach I'm taking, if you make $\$ 150,000$ or less, you will see a tax cut. If you're making $\$ 250,000$ a year or more, you're going to see a modest increase. What I'm trying to do is create a sense of balance and fairness in our tax code. One thing I think we can all agree on is that it should be simpler, so that you don't have all these loopholes and big stacks of stuff that you've got to comb through, which wastes a huge amount of money and allows special interests to take advantage of things that ordinary people cannot take advantage of.

\subsection{Transcript of Exchange between Warren and McCain on} Quantitatively Defining Rich with a Crisp Set. A transcript of the exchange between Warren and McCain on quantitatively defining rich with a crisp set follows:

Warren: Okay, on taxes, define rich. Everybody talks about taxing the rich, but not the poor, the middle class. At what point—give me a number, give me a specific number—where do you move from middle class to rich? Is it $\$ 100,000$ ? Is it $\$ 50,000$ ? Is it $\$ 200,000$ ? How does anybody know if we don't know what the standards are?

McCain: Some of the richest people I've ever known in my life are the most unhappy. I think that rich should be defined by a home, a good job, an education, and the ability to hand to our children a more prosperous and safer world than the one that we inherited.

I don't want to take any money from the rich-I want everybody to get rich. (Audience laughs.) I don't believe in class warfare or redistribution of the wealth. But I can tell you, for example, there are small business men and women who are working 16 hours a day, seven days a week, that some people would classify as quote rich, my friends, and want to raise their taxes and want to raise their payroll taxes.

Let's have-keep taxes low. Let's give every family in America a \$7,000 tax credit for every child they have. Let's give them a $\$ 5,000$ refundable tax credit to go out and get the health insurance of their choice. Let's not have the government take over the health care system in America.

So I think if you are just talking about income, how about $\$ 5$ million? (Audience laughs.)

But seriously, I don't think you can-I don't think seriously that-the point is that I'm trying to make here, seriously - and I'm sure that comment will be distortedbut the point is that we want to keep people's taxes low and increase revenues.

And, my friend, it was not taxes that mattered in America in the last several years. It was spending. Spending got completely out of control. We spent money in ways that mortgaged our kids' futures.

My friends, we spent $\$ 3$ million of your money to study the DNA of bears in Montana. Now I don't know if that was a paternity issue or a criminal issue. (Audience laughs.) But the point is, it was $\$ 3$ million of your money. It was your money. And, you know, we laugh about it, but we cry, and we should cry because the Congress is supposed to be careful stewards of your tax dollars.

So what did they just do in the middle of an energy crisis when in California we are paying $\$ 4$ a gallon for gas? Went on vacation for five weeks. I guarantee you, two things they never miss: a pay raise and a vacation. And we should stop that and call them back and not raise your taxes. We should not and cannot raise taxes in tough economic times.

So it doesn't matter really what my definition of rich is because I don't want to raise anybody's taxes. I really don't. In fact, I want to give working Americans a better shot at having a better life, and we all know the challenges, my friends, if I could be serious.

Americans tonight in California and all over America are sitting at the kitchen table-recently and suddenly lost a job, can't afford to stay in their home, education for their kids, affordable health care. These are tough problems. These are tough problems. You talk to them every day. 


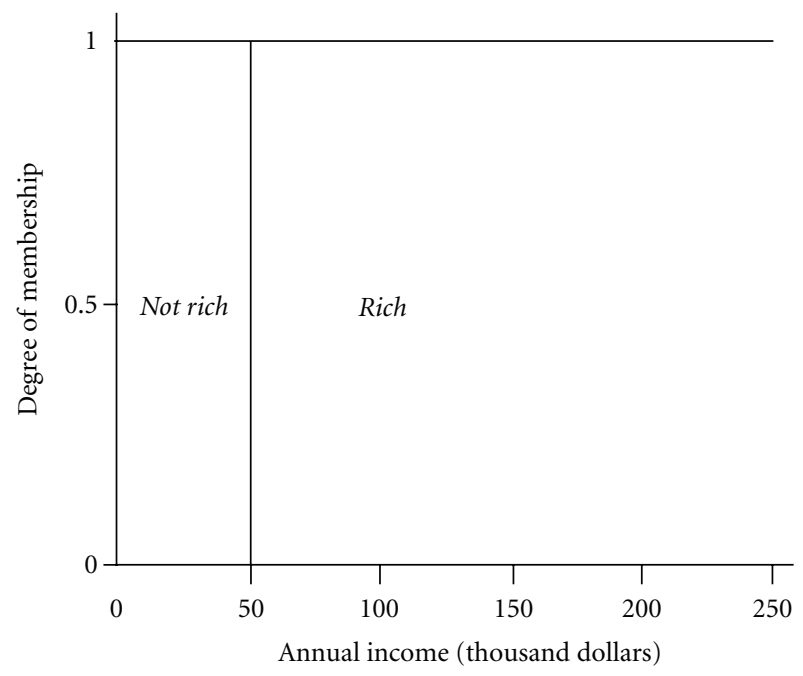

FIGURE 1: Warren's crisp sets for rich and not rich with his dividing line of $\$ 50,000$.

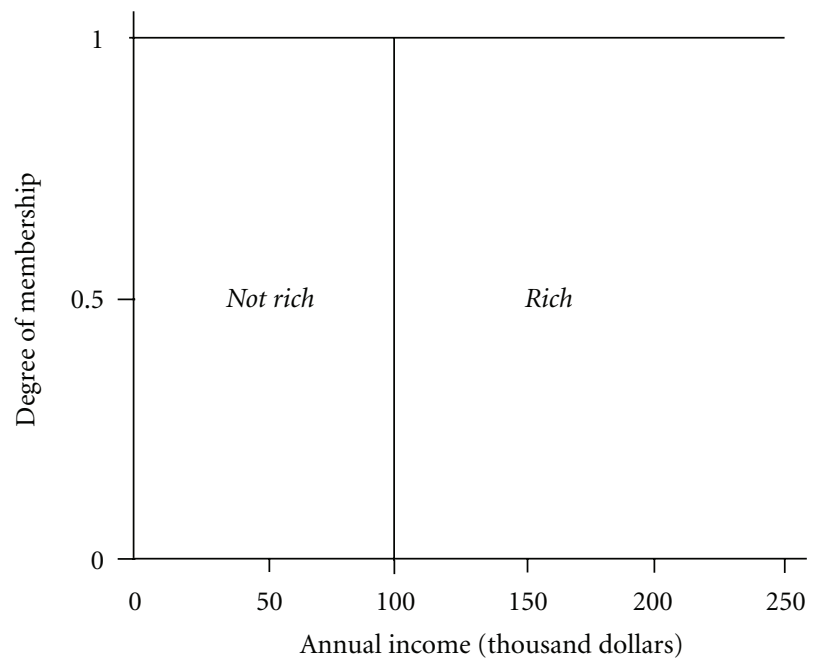

FIGURE 2: Warren's crisp sets for rich and not rich with his dividing line of $\$ 100,000$.

\section{Quantitatively Defining Rich with a Crisp Set}

3.1. Warren's Crisp Questions about Quantitatively Defining Rich with a Crisp Set. With his question, Warren wanted to know an exact number at which an individual becomes rich. He specifically asked McCain and Obama whether incomes of $\$ 50,000, \$ 100,000$, or $\$ 200,000$ are the dividing lines between rich and not rich. Warren's three dividing lines between rich and not rich can be illustrated using the crisp sets in Figures 1, 2, and 3.

According to Warren's crisp logic for his dividing line of $\$ 100,000$, an individual with an income of $\$ 99,999$ is not rich with a degree of membership of 1 in this crisp set whereas an individual with an income of $\$ 100,001$ is rich with a degree of membership of 1 in this crisp set.

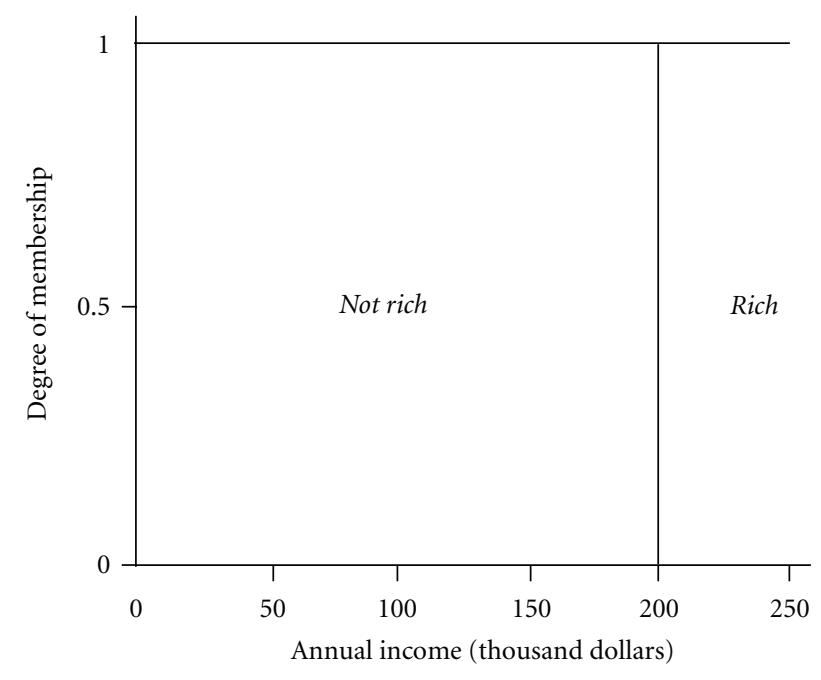

FIGURE 3: Warren's crisp sets for rich and not rich with his dividing line of $\$ 200,000$.

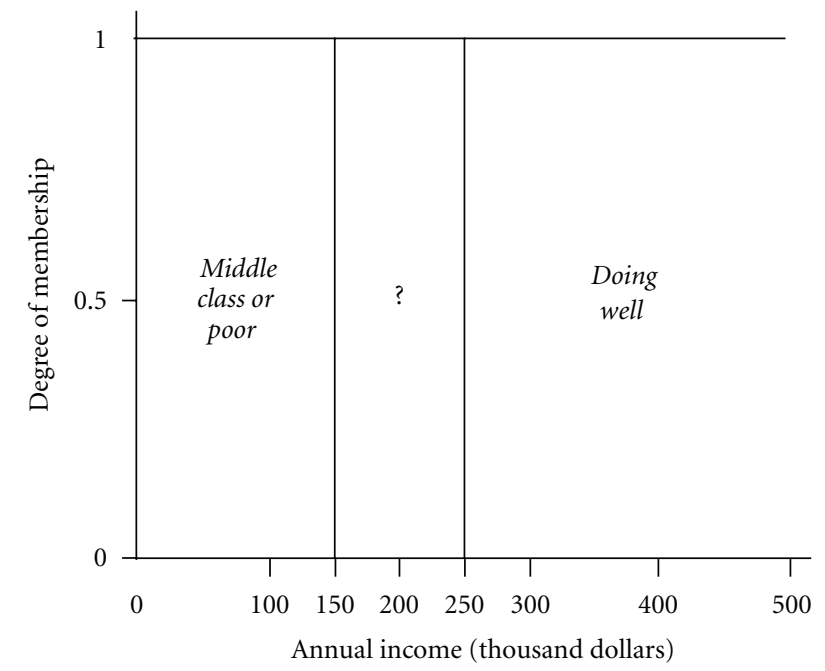

Figure 4: Obama's crisp sets for middle class or poor and doing well.

3.2. Obama's Crisp Answer in Quantitatively Defining Rich with a Crisp Set. In responding to Warren's question, Obama essentially defined anyone making $\$ 150,000$ or less as being in the middle class or being poor, and he defined anyone making \$250,000 or more as doing well. He didn't assign a linguistic qualifier for those making an income between $\$ 150,000$ and $\$ 250,000$. Obama's answer can be illustrated using the crisp sets in Figure 4.

According to Obama's crisp logic, an individual with an income of $\$ 249,999$ is undefined whereas an individual with an income of $\$ 250,001$ is doing well with a degree of membership of 1 in this crisp set.

3.3. McCain's Crisp Answer in Quantitatively Defining Rich with a Crisp Set. In responding to Warren's question, McCain essentially defined anyone earning \$5 million or 


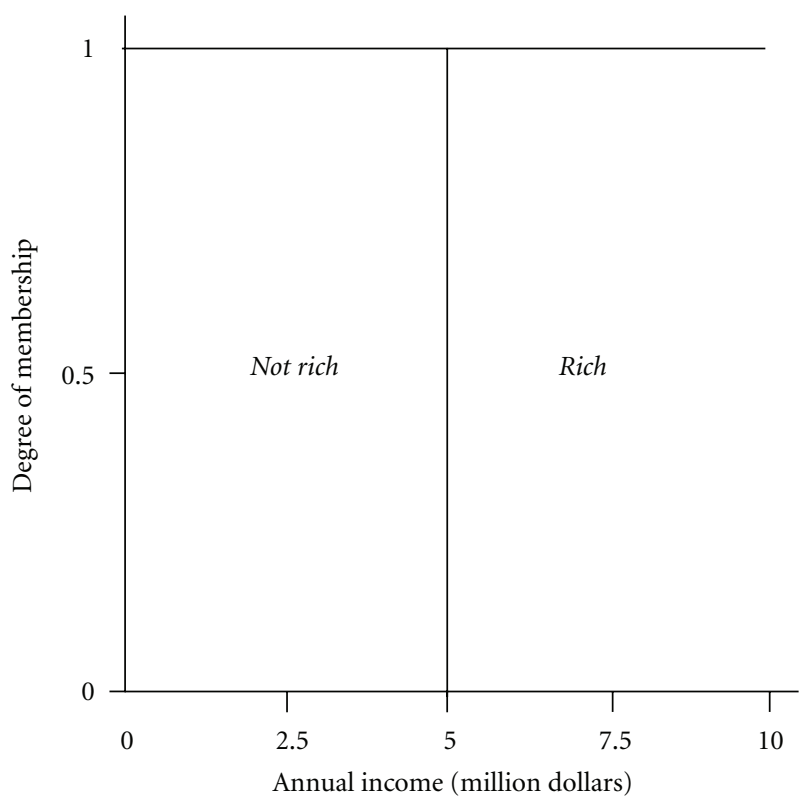

FIGURE 5: McCain's crisp sets for rich and not rich.

more as rich and anyone earning less than $\$ 5$ million as not rich. McCain's answer can be illustrated using the following crisp sets.

According to McCain's crisp logic, an individual with an income of $\$ 4,999,999$ is not rich with a degree of membership of 1 in this crisp set whereas an individual with an income of $\$ 5,000,001$ is rich with a degree of membership of 1 in this crisp set.

\section{Multiple Determinants of Financial Well-Being}

An individual's annual income does not solely determine whether or not he is rich, middle class, or poor. There are many different factors related to an individual's circumstances that affect his financial well-being and affect what annual income is needed to be rich, middle class, or poor:

(i) number of dependents,

(ii) family income,

(iii) geographical location,

(iv) assets,

(v) savings,

(vi) expenses,

(vii) debts,

(viii) investments,

(ix) inheritances,

(x) time period.

For example, an individual with no annual income, no dependents, no debts, and $\$ 10$ million in savings would be considered rich.

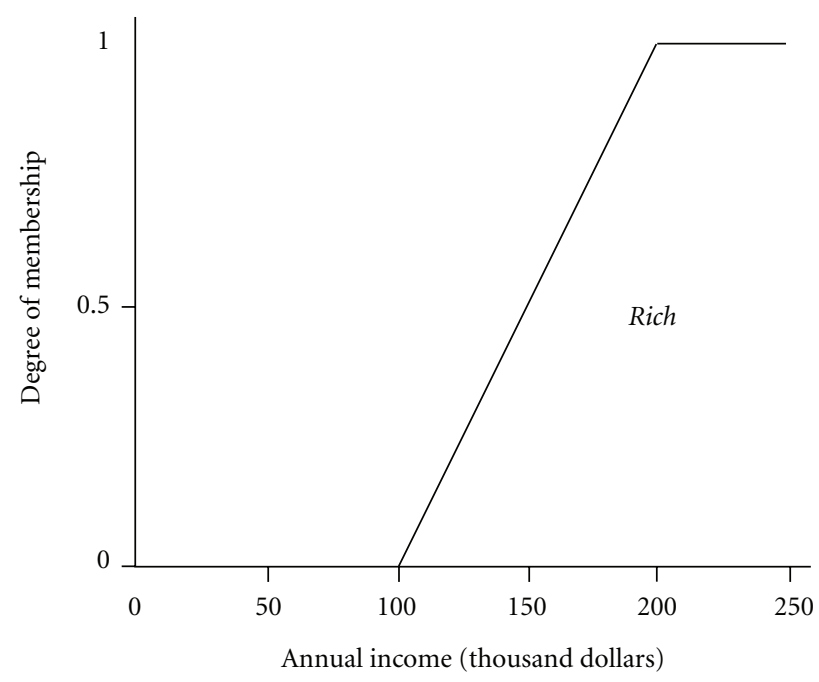

FIGURE 6: Fuzzy set for rich.

However, to answer Warren's question about annual income, one needs to make an assumption about the other factors affecting an individual's financial well-being. The assumption can be made that the individual's circumstances other than annual income are equivalent to those of the average American adult.

\section{Quantitatively Defining Rich with a Fuzzy Set}

5.1. Rich as a Fuzzy Set. There is no specific income level at which an individual goes from being not rich to being rich. Rich should be defined as a range of incomes in which different incomes have different degrees of richness associated with them. In fuzzy logic, a linguistic qualifier like rich is a fuzzy set, and different incomes have different degrees of membership in this fuzzy set.

Rich can be arbitrarily defined as an S fuzzy set with the following parameters. For incomes less than $\$ 100,000$, there is a membership of 0 in the rich fuzzy set. As income increases from $\$ 100,000$ to $\$ 200,000$, the membership in the rich fuzzy set increases from 0 to 1 with a constant slope. For incomes greater than $\$ 200,000$, there is a membership of 1 in the rich fuzzy set. This rich fuzzy set is as illustrated in Figure 6.

Then, for example, with an annual income of $\$ 140,000$, there is a degree of membership of 0.4 in the rich fuzzy set.

5.2. Fuzzy Questions for Warren about Quantitatively Defining Rich with a Fuzzy Set. In questioning McCain and Obama about the annual income needed for an individual to be rich, Warren first needed to specify in detail the individual's other circumstances affecting his financial wellbeing. Alternatively, he could have said that the individual's other circumstances were equivalent to those of the average American adult.

Then Warren should have separately asked for an income below which an individual is definitely not rich, a range of incomes between which an individual is rich to some degree, and an income above which an individual is definitely rich. 
This could be phrased as follows: "In the following queries, assume that all of the circumstances affecting an individual's prosperity are equivalent to those of the average American adult. Give me an annual income below which an individual is definitely not rich. Give me a range of annual incomes between which an individual is rich to some degree. Give me an annual income above which an individual is definitely rich." This is how one would define rich with a fuzzy set. To avoid overwhelming Obama, McCain, and the audience with too many queries at once, Warren could have waited for a response after each query before proceeding to the subsequent query.

5.3. Fuzzy Answers for Obama and McCain in Quantitatively Defining Rich with a Fuzzy Set. Obama and McCain first needed to make clear that the definition of rich varies considerably depending on many factors affecting an individual's financial well-being other than annual income. They should have stated their assumptions regarding the other factors or asked Warren for more details. Then they could have given their perception of what annual income is needed to be rich for the average American by providing an income below which an individual is definitely not rich, providing a range of incomes between which an individual is rich to some degree, and providing an income above which an individual is definitely rich.

This could be articulated as follows: "There are many different factors other than annual income that affect an individual's prosperity. If we make the assumption that these other factors are equivalent to those of the average American adult, then in my perception, an individual with an income less than $\$ 100,000$ per year is definitely not rich. As an individual's income rises from $\$ 100,000$ to $\$ 200,000$ per year, he is rich to some degree and his degree of being rich steadily increases. An individual with an income greater than $\$ 200,000$ per year is definitely rich." This is how one would define rich with a fuzzy set.

\section{Qualitative Definitions, Crisp Quantitative Definitions, and Fuzzy Quantitative Definitions of Imprecise Words}

An imprecise word like rich should be considered to have qualitative definitions and quantitative definitions. An imprecise word like rich should be considered to have two types of quantitative definitions: crisp quantitative definitions and fuzzy quantitative definitions.

A qualitative definition of rich can be found in MerriamWebster's Online Dictionary [8], which defines rich as "having abundant possessions and especially material wealth." Although there are other definitions of rich in this dictionary, this is the qualitative definition of rich that is most related to Warren's question.

Crisp quantitative definitions are those made with crisp sets. Crisp quantitative definitions of rich by Warren are in Section 3.1 and Figures 1-3. A crisp quantitative definition of rich by Obama is in Section 3.2 and Figure 4. A crisp quantitative definition of rich by McCain is in Section 3.3 and Figure 5.

Fuzzy quantitative definitions are those made with fuzzy sets. A fuzzy quantitative definition of rich by the author of this research paper is in Section 5.1 and Figure 6. It should be realized that while quantitative definitions of imprecise words can be made with crisp sets or fuzzy sets, only fuzzy sets can model the imprecision of words, so crisp sets have extremely limited value in modeling imprecise words.

There are multiple qualitative definitions because a word can have multiple meanings and because different ways of defining a word can be employed. That is, different dictionaries use different descriptions to convey the meaning of the same word.

There are multiple crisp quantitative definitions because different individuals have different perceptions of the crisp set for imprecise words. This was seen in the differing perceptions by Warren, McCain, and Obama. There are multiple fuzzy quantitative definitions because different individuals have different perceptions of the fuzzy set for imprecise words. Furthermore, the fuzzy or crisp quantitative definition of a word can vary considerably depending on many factors, such as the multiple determinants of financial well-being listed in Section 4.

It is important to distinguish between qualitative definitions and quantitative definitions of imprecise words. These terms were coined by the author of this research paper, Ashu M. G. Solo. Furthermore, it is important to distinguish between crisp quantitative definitions and fuzzy quantitative definitions of imprecise words. These terms were also coined by the author of this research paper, Ashu M. G. Solo.

\section{Linguistic Hedges}

Linguistic qualifiers by themselves can be restrictive in describing fuzzy variables, so linguistic hedges can be used to supplement linguistic qualifiers through numeric transformation. For example, a very hedge can square the initial degree of membership $\mu$ in a fuzzy set:

$$
\mu_{\text {very rich }}(\text { Jane })=\left[\mu_{\text {rich }}(\text { Jane })\right]^{2} .
$$

That is, if an individual named Jane has a membership of 0.7 in the rich fuzzy set, she will have a membership of 0.49 in the very rich fuzzy set.

Following are some other possible linguistic hedges:
(1) somewhat,
(2) more or less,
(3) extremely,
(4) above,
(5) below,
(6) not.

\section{Conclusion}

Humans think in imprecise and vague terms. Consequently, human language is inherently imprecise and vague. A 
major problem arises when people try to bring precision into situations where it does not apply, such as defining human linguistic terms like rich as being greater than a single precise annual income. Because Obama, McCain, and Warren were unfamiliar with fuzzy logic, Warren was unable to properly ask this query and Obama and McCain were unable to properly answer it. All of them actually made fools of themselves in attempting to ask or answer this query with crisp logic. An understanding of the basic principles of fuzzy logic can be extremely useful in asking proper questions and giving proper answers about quantitatively defining imprecise linguistic terms. Imprecise linguistic terms in natural languages should be considered to have qualitative definitions, crisp quantitative definitions, and fuzzy quantitative definitions. Fuzzy logic can be extremely useful in public policy and law, which are full of uncertainties and imprecision.

The contributions of this research paper are as follows:

(1) It shows that an understanding of fuzzy logic is required to properly ask and answer queries about quantitatively defining imprecise linguistic terms.

(2) It shows that fuzzy logic was actually required during a US presidential forum to properly ask and answer a query about defining rich.

(3) It distinguishes between qualitative definitions and quantitative definitions of imprecise linguistic terms.

(4) It distinguishes between crisp quantitative definitions and fuzzy quantitative definitions of imprecise linguistic terms.

These contributions are useful in computational linguistics, applied linguistics, theoretical linguistics, humancomputer interaction, natural language processing, soft computing, and intelligent systems. Furthermore, these contributions are useful in asking and answering queries in general conversation, politics, public policy, economics, education, and many other fields.

The author of this research paper has a published conference paper [9] and published op-ed article [10] that describe an earlier version of this research work. An earlier version of the research described in this paper was published as [9]. A condensed op-ed article describing the research in [9] was published as [10]. However, [9] and [10] do not describe the terms qualitative definitions, quantitative definitions, crisp quantitative definitions, and fuzzy quantitative definitions for imprecise linguistic terms.

\section{References}

[1] L. A. Zadeh, "Fuzzy sets," Information and Control, vol. 8, no. 3, pp. 338-353, 1965.

[2] L. A. Zadeh, "Outline of a new approach to the analysis of complex system and decision processes," IEEE Transactions on Systems, Man and Cybernetics, vol. 3, no. 1, pp. 28-44, 1973.

[3] A. Kaufmann and M. M. Gupta, Fuzzy Mathematical Models in Engineering and Management Science, North-Holland, Amsterdam, The Netherlands, 1988.

[4] M. M. Gupta, L. Jin, and N. Homma, "Fuzzy sets and systems: an overview," in Static and Dynamic Neural Networks: From
Fundamentals to Advanced Theory, pp. 636-644, John Wiley \& Sons, Hoboken, NJ, USA, 2003.

[5] A. M. G. Solo and M. M. Gupta, "Uncertainty in computational perception and cognition," in Forging New Frontiers: Fuzzy Pioneers I: Studies in Fuzziness and Soft Computing, M. Nikravesh, J. Kacprzyk, and L. A. Zadeh, Eds., pp. 251-266, Springer, New York, NY, USA, 2007.

[6] M. M. Gupta and A. M. G. Solo, "On the morphology of uncertainty in human perception and cognition," in Proceedings of the First Interdisciplinary CHESS Interactions Conference, Saskatoon, Saskatchewan, Canada, 17-20 August 2009, pp. 257-271, World Scientific, River Edge, NJ, USA, 2009.

[7] Saddleback Civil Forum on the Presidency, Saddleback Church, Lake Forest, Calif, USA, 2008, http://www.saddlebackcivilforum.com/thepresidency/.

[8] Merriam-Webster's Online Dictionary, Merriam-Webster, Springfield, Mass, USA, http://www.merriam-webster.com/ dictionary/rich.

[9] A. M. G. Solo, M. M. Gupta, N. Homma et al., "Obama, McCain, and Warren needed fuzzy logic to define 'rich' by income," in Proceedings of the 2009 International Conference on e-Learning, e-Business, Enterprise Information Systems, and eGovernment (EEE '09), pp. 265-270, CSREA Press, Las Vegas, Nev, USA, July 2009.

[10] A. M. G. Solo, "Defining 'Rich"” OpEdNews, 2009, http://www.opednews.com/articles/Defining-Rich-by-AshuM-G-Solo-091122-857.html. 

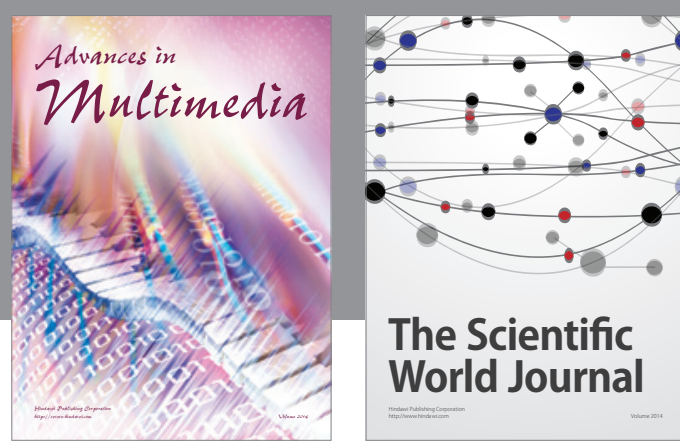

The Scientific World Journal
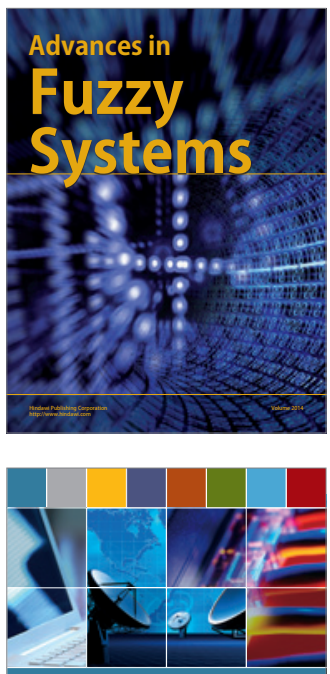

Computer Networks and Communications
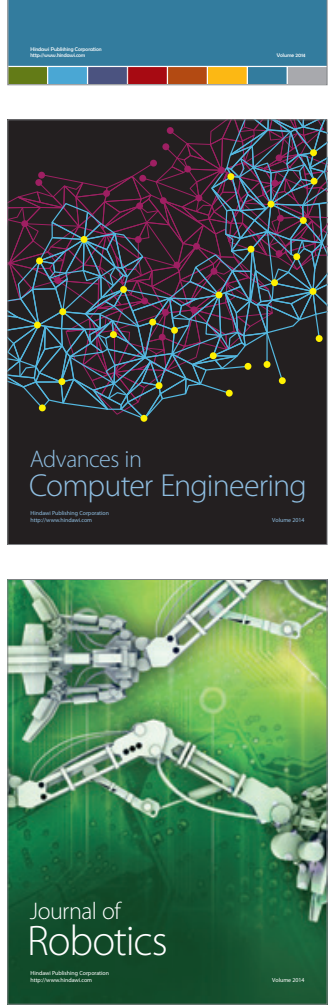
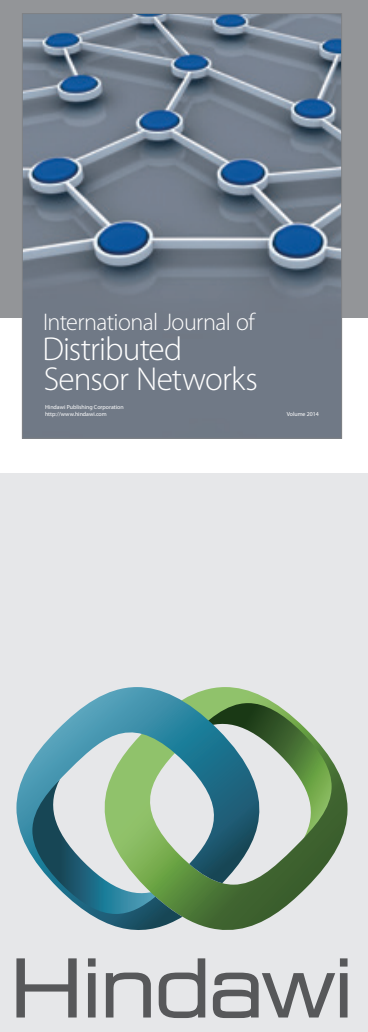

Submit your manuscripts at

http://www.hindawi.com
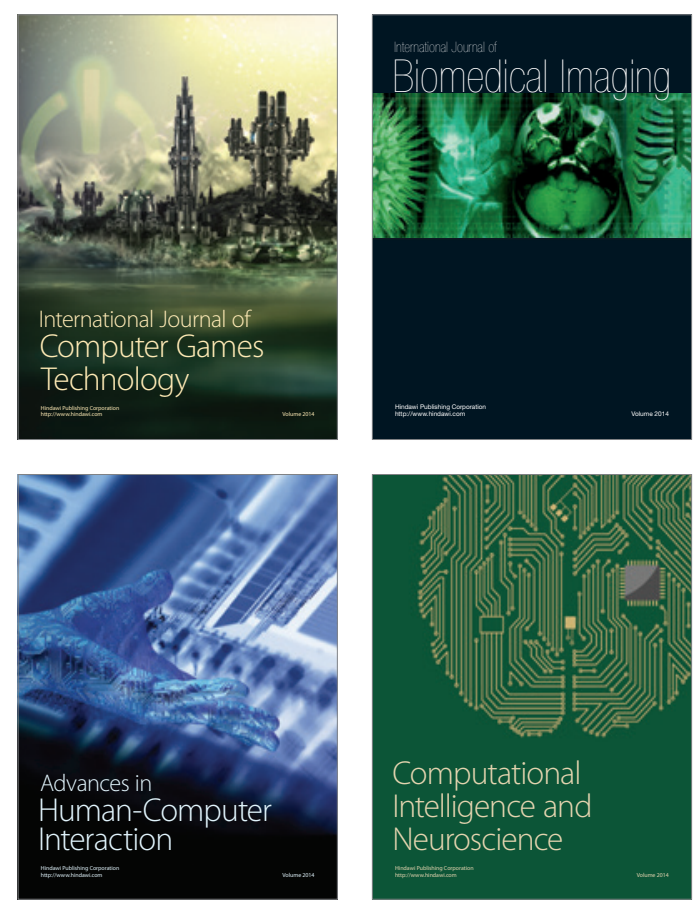
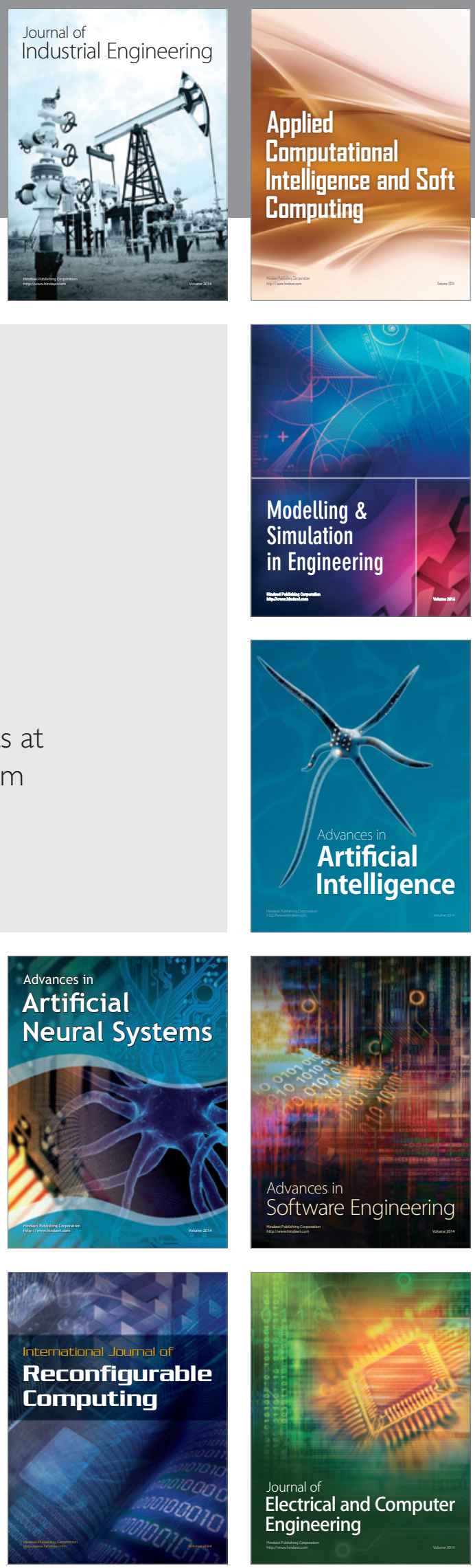